Original Article (short paper)

\title{
Dual-task demands in various motor skills through Parkinson's disease progression
}

\author{
Tatiana Beline de Freitas ${ }^{1}$, Keyte Guedes da Silva ${ }^{2}$, Rosemeyre Alcarde Nuvolini² ${ }^{2}$,

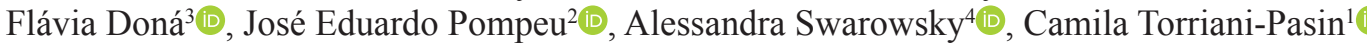 \\ ${ }^{1}$ Universidade de São Paulo, USP, Laboratory of Motor Behavior, School of Physical Education and Sport, São Paulo, \\ SP, Brazil; ' ${ }^{2}$ niversidade de São Paulo, USP, Departamento de Fisioterapia, Fonoaudiologia e Terapia Ocupacional, \\ Faculdade de Medicina, São Paulo, SP, Brazil,; ${ }^{2}$ Universidade Anhanguera de São Paulo, Programa de Mestrado em \\ Reabilitação do Equilíbrio Corporal e Inclusão Social, São Paulo, SP, Brazil; ${ }^{4}$ Universidade Estadual de Santa Catarina, \\ UDESC, Physical Therapy Postgraduate Program, Physical Therapy Department, Florianópolis, SC, Brazil
}

\begin{abstract}
Aim: The aim of this study was to investigate the effects of adding a cognitive task on the performance of three different motor tasks with different demands, discrete skills, serial skills and continuous skills, by individuals with mild, moderate, and severe idiopathic Parkinson' disease (PD). We also investigate the effect of the cognitive task in the secondary task and the cost of the dual-task. Method: This is a cross-sectional study. Individuals with idiopathic PD were divided in three groups with respect to motor severity (mild, moderate and severe groups). Participants' performances were assessed in single and DT conditions including Sit-to-Stand test (SST), Timed Up and Go (TUG), and 10-meter Walk test (T10W). Cognitive task used was verbal fluency Results: The results show that dual task impact the performance of all primary tasks. DT negatively affects the performance of the motor tasks. And there is a different impact according the severity of the disease, severe ones are more affected than mild and moderate. Conclusion: In conclusion, adding a concurrent cognitive task negatively affected the performance of discrete, serial and continuous motor tasks, and this effect is more noticeable in severe than in mild patients. Under dual-task conditions, patients improved their cognitive task performance for gait and TUG, suggesting a prioritization of the secondary task for these tasks. There was no difference between the costs of the three tasks.
\end{abstract}

Keywords: parkinson's disease, dual-task, postural control.

\section{Introduction}

Individuals with Parkinson's disease (PD) have motor performance impairment in dual-task (DT) conditions ${ }^{1-4}$ due loss of automaticity and reduced cognitive resources, including the ability to divide their attentional demand between competing $\operatorname{tasks}^{5,6}$. These deficits increase the risk of falling and restrict the performance of the activities of daily living ${ }^{2,7,8}$.

Competition between two tasks of different natures results in decreased performance in one or both tasks ${ }^{9-12}$. Therefore, when additional demands are imposed by a cognitive task that must be performed simultaneously with a postural task, balance becomes increasingly vulnerable ${ }^{12,13}$. Studies have shown that individuals with PD prioritized cognitive tasks over motor tasks, revealing an inadequate task prioritization strategy ${ }^{14-16}$. When a second task is performed simultaneously, the change in performance is called interference, or the DT effect ${ }^{17}$.

Different combinations of factors including demographic characteristics, disease severity, fall history, fear of falling, other gait and mobility measures, freezing of gait, balance, balance confidence, muscle power, cognition, and depression have been identified as significant predictors of gait and mobility performance in single and DT conditions ${ }^{18}$. In addition, the nature and difficulty of the task is emphasized as being of great relevance for the performance of the task ${ }^{17}$. According to Plummer \& Eskes $^{17}$, different tasks should be tested to confirm the impact of DT on individuals with PD.

Despite several studies that have shown the DT effects on PD individuals, it is not known whether the costs of this interference are affected due to disease severity in different motor skills. In this context, motor skill refers to a task with a specific purpose to be achieved ${ }^{19}$.

Therefore, the aim of this study was to investigate the effects of adding a cognitive task on the performance of three different motor tasks by individuals with PD according to the disease stage. This information could influence decision-making regarding the use of DT in clinical practice. The hypothesis is that the introduction of the concurrent task will affect the most impaired individuals to a greater extent and this will depend on the task characteristic.

\section{Method}

\section{Participants}

This is a cross-sectional study that included patients 36 patients ( 24 men and 12 women) with idiopathic PD 
diagnosed according to the criteria of the UK Brains Bank Parkinson's Society ${ }^{20}$, in stages $1.0-4.0$ on the Hoehn \& Yahr (HY) modified scale ${ }^{21}$; patients were $50-80$ years old. In addition, all subjects were being treated with Levodopa and/or its synergists and were able to walk independently. The study excluded patients with significant biomechanical, cardiovascular, or respiratory changes that could impair motor-task performance.

All participants agreed to participate in the study and signed consent forms. The study was approved by the Ethics Committee of the Medical School of the Federal University of São Paulo, Brazil (226.672).

\section{Methodological Procedures}

A trained examiner led the data collection, which followed a structured protocol.

Single- and dual-task accomplishments were assessed during "on" periods, about 40 minutes to two hours after Levodopa was administered. Initially, demographic data (age, gender, and educational level) were screened to characterize the sample. Disease severity was assessed on the HY modified scale $^{21}$. Cognitive functions were evaluated using Minimetal State Examination (MMSE) ${ }^{22}$ and Montreal Cognitive Assessment (MoCA $)^{23}$. Motor progression was assessed using the Unified Scale Evaluation of Parkinson's Disease - Unified PD Rating Scale (UPDRS) section III ${ }^{24}$.

The subjects were separated into mild, moderate and severe through the HY scale ${ }^{21}, 1$ and 1.5 were considered mild, 2 and 2.5 were considered moderate and 3 and 4 were considered severe ${ }^{25,26}$.

\section{Cognitive task evaluation}

Cognitive task evaluation was conducted using verbal fluency $(\mathrm{VF})^{27-29}$, which was applied by first asking subjects, while seated, to evoke as many words as possible in a specific semantic category over 30 seconds. The categories used were names, animals, fruits, foods, and clothing, both classified as easy according to Krampe, Schaefer, Lindenberger, Baltes ${ }^{30}$.

Then, VF was performed simultaneously with each of three motor tasks: Sit-to-Stand (SST), Timed Up and Go (TUG), and 10-meter Walk test (T10W). A separate semantic category was used for the seated position and each of the three motor tasks. The categories were randomly assigned, and each was used only once.

\section{Motor skills assessment}

Three motor skills with different demands were chosen. The three motor tasks in the single and dual task conditions were randomized to remove the effect of the order and the influence of fatigue in the last attempts. According Schmidt and Lee ${ }^{31}$, all skills can be classified as discrete skills, which usually have a defined beginning and ending; serial skills, often considered a series of discrete skills together to build up a new, more complicated skill; and continuous skills that have no particular beginning or end. SST, TUG and $\mathrm{T} 10 \mathrm{~W}$ represent each of the categories, respectively.

For each of the three motor tasks selected, the subjects were randomly evaluated in single- and dual-task conditions. Subjects received appropriate instructions for all tasks and conditions. An attempt to familiarize each task with verbal instructions and demonstrations was performed, to better understand the task to be performed.

SST was performed in por on a chair with seat height of approximately $44 \mathrm{~cm}$, according to the description in Duncan, Leddy and Earhart ${ }^{32}$. The subject sat on the center of the chair, with back straight, feet parallel and separated a distance equivalent to shoulder width, and arms folded across the chest. From this position, the patient was asked to get up and sit back down five times, as quickly as possible. A verbal command was given at the beginning and end of the test. No verbal incentives were given during the performance of the test. The time spent to complete the test was measured in seconds and there was no rest between the trials.

The TUG test required the subject to sit in the same chair in the same position as for the SST task. The subject was instructed to get up from the chair, walk three meters and return to and sit on the same chair as quickly as possible without running. The time spent to complete the test was measured in seconds ${ }^{33}$.

TUG was considered as a serial task because the individual needs to perform four discrete tasks, in case standing, walking, taking a turn and sitting down.

The T10W test was also timed in seconds, and subjects were asked to walk as quickly as possible without running. First, four marks were placed on the floor. The first was made 1.2 meters before the beginning of a $10-\mathrm{m}$ course. The second marked the beginning of the $10-\mathrm{m}$ course, and the third marked its end. Finally, the fourth marked $1.2 \mathrm{~m}$ after the end of the course. Subjects' times were recorded from the point when they crossed the starting line for the 10-m course and ended when they reached its finish line. To account for phase-gait acceleration and deceleration, the times taken to cover the initial and final $1.2-\mathrm{m}$ distances were discarded ${ }^{34}$.

For all three tasks, the single-task condition recorded the time in seconds taken to complete the task. The dual-task condition recorded the time in seconds taken to execute the task and the number of words recorded by the examiner during the test. The time of each trial was recorded with a stopwatch, starting synchronized with the command to start the task and final synchronized with the time that the individual finished the task. If the individual had episodes of bradykinesia or freezing, the timer was not interrupted, and the task was expected to finish. The task was interrupted only if the participant requested it.

All evaluations were performed in the morning. To avoid fatigue, a two-minute rest period was provided between tasks. 


\section{Statistical Analyses}

The dependent variables were performance time and verbal fluency (number of words/ execution time) verbalized during the tasks and baseline.

In addition, the cost of the dual task (CDT) was calculated as the difference between performance on the dual task and performance on the single task for each measurement, as described by McDowd ${ }^{35}$ : CDT $(\%)=[($ dual task - single task $)$ / single task] $\times 100 \%$.

Descriptive statistics were performed and presented as the mean (standard deviation). The Shapiro Wilk test was used to check the normality of the data. One-way ANOVA was used for sociodemographic and clinical characterization of the groups.
To check the variations in the dependent variables, repeated measures ANOVA ( $3 \times 3)$ was used with Tukey post hoc testing. All statistical analyses were performed using IBM SPSS version 22 software and a significance level $\leq 0.05$.

\section{Results}

The study included 36 patients ( 24 men and 12 women) who were divided into three groups according to disease severity. There was a difference between the groups for the UPDRS III, which quantifies the motor deficits related to the disease. Table 1 shows the subjects' clinical and demographic characteristics

Table 1- Sociodemographic and clinical characterization of patients with Parkinson's disease

\begin{tabular}{lcccc}
\hline & Mild & Moderate & Severe & $p$ value \\
\hline Gender (M/F) & $9 / 3$ & $8 / 4$ & $7 / 5$ & - \\
Age (years): [m (SD); median] & $66.75(8.13) ; 66.0$ & $69.34(7.75) ; 72$ & $74.41(6.22) ; 74.5$ & 0.48 \\
Educational level (years): [m (SD); median] & $9.16(5.57) ; 8.0$ & $9.58(4.37) ; 10.5$ & $8.91(4.71) ; 11.0$ & 0.94 \\
MMSE [m (SD); median] & $28.08(0.59) ; 28.0$ & $26.75(0.75) ; 28.0$ & $23.34(1.28) ; 24.5$ & $0.003^{\mathrm{bc}}$ \\
MoCA [m (SD); median] & $23.33(3.22) ; 24.0$ & $22.16(3.4) ; 22.5$ & $18.83(6.01) ; 19.0$ & 0.46 \\
UPDRS [m (SD); median] & $13.5(5.46) ; 13.5$ & $19.25(6.28) ; 19.0$ & $21.5(3.31) ; 21.5$ & $0.02^{\mathrm{ab}}$ \\
H\&Y & $1.0: 6 / 1.5: 6$ & $2.0: 2 / 2.5: 10$ & $3.0: 4 / 4.0: 8$ & - \\
\hline
\end{tabular}

Legend: Characterization of the participants. M: male; m: mean; F: female; H\&Y: Hoehn \& Yahr modified; MMSE: Mini-metal State Examination; MoCA: Montreal Cognitive Assessment; UPDRS: Unified Scale Evaluation of Parkinson's disease - Section III; ${ }^{\text {a: }}$ difference between mild and moderate groups; ${ }^{\text {b}}$ : difference between mild and severe groups; ${ }^{c}$ : difference between moderate and severe groups

\section{Motor Tasks Performance}

Table 2 shows the results of the SST, TUG, and T10W tasks performed in single- and dual-task conditions. For all three tasks, there was a significant difference between the two conditions, indicating that secondary tasks negatively affected performance of SST ( $p=0.01 ; \mathrm{F}=7.54)$, TUG ( $p=$
$0.00 ; \mathrm{F}=41.85)$, and T10W $(p=0.00 ; \mathrm{F}=26.88)$. There was interaction effect between condition (single and dual-task) and group for SST $(p=0.032 ; \mathrm{F}=3.81)$, TUG $(p=0.001$; $\mathrm{F}=8.60)$ and $\mathrm{T} 10 \mathrm{~W}(p=0.027 ; \mathrm{F}=4.04)$. For intergroup analyses, the difference was between mild and severe groups for all three tasks, and between moderate and severe for TUG and T10W.

Table 2 - Sit-to-Stand test, Timed Up and Go test, and 10-Meter Walk test, single- and dual- task

\begin{tabular}{|c|c|c|c|c|c|}
\hline & Mild & Moderate & Severe & p value & Effect size \\
\hline SST single task $[\mathrm{m}(\mathrm{SD})]$ & $14.7(2.35)$ & $17.34(6.89)$ & $18.53(6.69)$ & \multirow{2}{*}{$0.01^{* b}$} & \multirow{2}{*}{0.76} \\
\hline $\mathrm{SST}$ dual task $[\mathrm{m}(\mathrm{SD})]$ & $16.35(4.94)$ & $19.79(7.87)$ & $35.7(30.65)$ & & \\
\hline TUG single task [m(SD)] & $9.35(1.86)$ & $13.91(5.39)$ & $15.97(4.48)$ & \multirow{2}{*}{$0.00^{* \mathrm{~b} c}$} & \multirow{2}{*}{0.95} \\
\hline TUG dual task [m(SD)] & $11.88(3.48)$ & $16.68(5.95)$ & $25.21(9.4)$ & & \\
\hline T10W single task $[\mathrm{m}(\mathrm{SD})]$ & $6.59(1.18)$ & $8.87(3.54)$ & $11.99(4.59)$ & \multirow{2}{*}{$0.00^{* \mathrm{~b} c}$} & \multirow{2}{*}{0.99} \\
\hline T10W dual task [m(SD)] & $8.28(1.41)$ & $10.87(4.79)$ & $17.31(9.06)$ & & \\
\hline
\end{tabular}

Legend: SD: standard deviation; SST Sit-to-Stand test (sec); TUG: Timed Up and Go test (sec); T10W: 10-meters Walk test (sec); ${ }^{*}$ difference between single and dual task; ${ }^{\text {a: }}$ difference between mild and moderate groups; ${ }^{\text {b}}$ : difference between mild and severe groups; ${ }^{\mathrm{c}}$ : difference between moderate and severe groups 


\section{Verbal Fluency Performance}

Table 3 shows the results of the VF task performed while seated and in dual tasks. The comparison between VF in singleand dual-task conditions showed a significant difference $(p=0.00$; $\mathrm{F}=27.78$ ), without interaction effect between condition (single and dual-task) and group ( $p=0.57 ; \mathrm{F}=0.72)$. In the intergroup analyses VF in single condition showed a significant difference to VF-TUG ( $p=0.07 ; \mathrm{F}=8.28)$ and VF-T10W ( $p=0.00 ; \mathrm{F}=34,49)$. For the VF-SST, there was no significant difference between VF while seated and VF-SST ( $p=0.99 ; \mathrm{F}=0.00)$. For post-hoc analyses, the difference was between mild and severe groups $(p=0.001)$ and between moderate and severe $(p=0.02)$ for TUG, T10W, and single condition (Table 3 ).

Table 3 - Verbal fluency in dual tasks compared to the verbal fluency while seated

\begin{tabular}{|c|c|c|c|c|c|}
\hline & Mild & Moderate & Severe & p value & Effect size \\
\hline VF (seated) $[\mathrm{m}(\mathrm{SD})]$ & $0.39(0.15)$ & $0.38(0.17)$ & $0.2(0.09)$ & $0.03^{b c}$ & 0.898 \\
\hline VF-SST [m(SD)] & $0.38(0.11)$ & $0.34(0.11)$ & $0.24(0.13)$ & 0.99 & 0.500 \\
\hline VF -TUG [m(SD)] & $0.57(0.2)$ & $0.45(0.17)$ & $0.26(0.14)$ & $0.00^{*} \mathrm{bc}$ & 0.798 \\
\hline VF-T10W [m(SD)] & $0.73(0.22)$ & $0.63(0.24)$ & $0.5(0.35)$ & $0.00^{*} \mathrm{bc}$ & 0.850 \\
\hline
\end{tabular}

\section{Comparing the CDT of Each Task}

Table 4 shows the comparison of the CDTs for performing a primary task in dual task condition; the analyses showed that there was no difference among the tasks $(p=0.60$; $\mathrm{F}=0.339$ ).

Table 4 - Cost of dual task (CDT) in Sit-to-Stand test, Timed Up and Go test, and 10-meter Walk test

\begin{tabular}{|c|c|c|c|c|c|}
\hline & Mild & Moderate & Severe & p value & Effect size \\
\hline $\mathrm{SST}(\%)[\mathrm{m}(\mathrm{SD})]$ & $10.13(22.4)$ & $16.02(23.58)$ & $87.96(34,56)$ & & \\
\hline TUG (\%)[m(SD)] & $26.15(21.55)$ & $21.83(20.32)$ & 58.5 (37.78) & 0.60 & 0.102 \\
\hline T10W (\%)[m(SD)] & $26.29(12.83)$ & $21.87(13.32)$ & $41.96(41.02)$ & & \\
\hline
\end{tabular}

Legend: SD: standard deviation; SST: Sit-to-Stand test; TUG: Timed Up and Go test; 10WT: 10-meter Walk test

\section{Discussion}

The first aim of this study was to investigate the effects of a cognitive task that imposed competing demands on the ability of PD patients to perform three motor tasks of different complexities. The cognitive task performed concurrently with a motor-skill task, whether the SST, TUG, or $\mathrm{T} 10 \mathrm{~W}$, negatively affected motor-skill task performance. The introduction of the cognitive task concomitant to the motor task affects patients classified as mild and severe. And the cognitive task affects more the severe patients than the mild ones for all three tasks, and severe more than moderate patients for TUG and T10W.

It is well known that when a concurrent cognitive task is performed by PD patients, there is an impairment in the performance of the primary task $\mathrm{k}^{1,2,4,10,12,36-42}$. Our results are in accordance with those in the literature; however, the vast majority of studies have introduced a competing cognitive task with walking tasks $1,4,12,36,37,39-42$. The novelty of our study focused on the effect of the performance of dual tasks and other motor skills, including sit-to-stand. Previous studies have shown the worsening of PD patients' performance on the SST task ${ }^{2}$ and on writing ${ }^{43}$ when these tasks were performed in a pair of dual tasks that included VF.
There were differences among the groups at the baseline regarding the number of words spoken in the sitting position for the mild and severe groups and for moderate and severe groups. The severe group presented a difference in relation to the other groups in relation to cognition measured through MMSE, and the deterioration of cognition appears in the number of words evoked. Our data reinforce the cognitive deterioration with the progression of the disease already described in the literature ${ }^{44-46}$. Another point is that the severe group presented greater motor impairment in the UPDRS, especially subjects with HY 4 were included, in that sense individuals with severe disability but still able to walk or unassisted stand were included ${ }^{25}$, and that, probably, severe patients have to use attention for the motor activities, and, consequently, present difficulty in dividing the attentive demand among the tasks.

During dual-task conditions, VF improved in TUG and T10W, which did not occur for SST, which was not expected. This result is new in the literature and not corroborated by other studies ${ }^{10}$, being performance in both tasks in dual-task conditions impaired. Dual-task studies have shown a decline of performance either in walking or the concurrent task $\mathrm{k}^{47}$. Only one study demonstrated concurrent task improvements and walking declines under dual-task conditions ${ }^{48}$, which is consistent with trade-offs between tasks and prioritization of the concurrent task in walking tasks. 
Fok, Farrell, McMeeken ${ }^{11}$ identified prioritization of motor tasks over cognitive tasks. The authors found prioritizing gait in dual-task conditions is a compensatory strategy to manage short, slow steps, and in this condition, individuals with mild-to-moderate PD take more strides and increase their gait speed. Nocera, Roemmich, Elrod, Altmann, Hass ${ }^{42}$ found prioritization of motor tasks over cognitive ones at the beginning of gait tasks. Moreover, Kelly, Eusterbrock, Shumway-Cook ${ }^{1}$ argued that the addition of a secondary task decreases walking speed, stride length decreased symmetry and coordination between the legs and increased the variability of the steps, and the cost of a concurrent cognitive tasks increased when compared to the condition of sitting.

In a VF test lasting one minuten addition, Rodrigues, Yamashita, Chiappetta ${ }^{49}$ found the participants have spoken the largest number of words in the first 15 seconds.

Baker, Rochester, Nieuwboer ${ }^{50}$ reported that in dual-task conditions, PD patients optimized cognitive tasks over gait or postural tasks, compromising the stability of their balance and thus their security when walking. Fernandes, Sousa, Couras, Rocha, Tavares ${ }^{2}$ suggested that a deficit in postural control is the main cause of worsened dual-task performance. The authors observed greater posterior-to-anterior displacement of the center of pressure during sitting and standing tasks when they were performed in dual-task conditions, suggesting reduced stability in these conditions. Increased displacement of the center of pressure was also observed when the patient was asked to remain standing while performing a cognitive $\operatorname{task}^{10,51}$.

There was no difference in the cost of the dual task for the three tasks investigated. Kelly, Eusterbrock, Shumway-Cook ${ }^{1}$ suggest that the severity of the disease may be associated with worsening gait under dual-task conditions and our results suggest that the same occurs in other motor tasks.

For a long time, the inclusion of DT in balance and gait training in individuals with PD was avoided in physiotherapy ${ }^{52}$ mainly because it was thought to aggravate gait disturbances and cause falls, and ours results contributed for that, especially for severe ones. However, current conceptual lines of physiotherapy postulate that adopting DT in task training would be a way to alleviate deficits in daily activities, and that this practice could be introduced during the rehabilitation of PD patients ${ }^{52-54}$. However, our results show that individuals with PD are impacted by the introduction of the secondary task, regardless of the characteristics of the task, and that severe individuals are more impacted, therefore, the training should be done safely and supervised.

The limitations of the study are related to focus of attention; no attention focus was requested on the primary or secondary task for the included individuals, which might have interfered in our results.

The secondary task affects the performance of the motor task, regardless of its characteristics, in individuals with PD. In the future, the training of different motor tasks could be implemented to investigate the effect of training these tasks.
In conclusion, adding a concurrent cognitive task negatively affected the performance of the discrete, serial and continuous motor tasks, and this effect is more noticeable in severe than in mild patients. Under dual-task conditions, patients improved their cognitive task performance for gait and TUG, suggesting a prioritization of the secondary task for these tasks. There was no difference between the costs of the three tasks.

\section{References}

1. Kelly VE, Eusterbrock AJ, Shumway-Cook A. A review of dual-task walking deficits in people with Parkinson's disease: motor and cognitive contributions, mechanisms, and clinical implications. Parkinsons Dis. 2012;2012:1-14. doi:10.1155/2012/918719.

2. Fernandes Â, Sousa ASP, Couras J, Rocha N, Tavares JMRS. Influence of dual-task on sit-to-stand-to-sit postural control in Parkinson's disease. Med Eng Phys. 2015;37(11):1070-1075. doi:10.1016/j.medengphy.2015.08.011.

3. Stegemoller EL, Wilson JP, Hazamy A, Shelley MC, Okun MS, Altmann LJP, et al. Associations between cognitive and gait performance during single- and dual-task walking in people with Parkinson disease. Phys Ther. 2014;94(6):757-766. doi:10.2522/ ptj.20130251.

4. Fernandes Â, Sousa ASP, Rocha N, Tavares JMRS. The influence of a cognitive task on the postural phase of gait initiation in Parkinson's disease: an electromyographic based analysis. Motor Control. 2016;19:1-28.

5. Wu T, Hallett M. A functional MRI study of automatic movements in patients with Parkinson's disease. Brain. 2005;128(10):22502259. doi:10.1093/brain/awh569.

6. Jankovic J. Parkinson's disease: clinical features and diagnosis. J Neurol Neurosurg Psychiatry. 2008;79(4):368-376. doi:10.1136/ jnnp.2007.131045.

7. Wong-Yu ISK, Mak MKY. Task- and Context-specific Balance Training Programme Enhances Dynamic Balance and Functional Performance in Parkinsonian Non-fallers: A Randomised Controlled Trial with Six-month Follow-up. Arch Phys Med Rehabil. 2015;96(12):2103-2111. doi:10.1016/j. apmr.2015.08.409.

8. van der Marck MA, Klok MPC, Okun MS, Giladi N, Munneke M, Bloem BR. Consensus-based clinical practice recommendations for the examination and management of falls in patients with Parkinson's disease. Parkinsonism Relat Disord. 2014;20(4):360369. doi:10.1016/j.parkreldis.2013.10.030.

9. Brauer SG, Woollacott MH, Lamont R, Clewett S, O'Sullivan J, Silburn $\mathrm{P}$, et al. Single and dual task gait training in people with Parkinson's disease: a protocol for a randomised controlled trial. BMC Neurol. 2011;11(1):1-6. doi:10.1186/1471-2377-11-90.

10. Fernandes Â, Coelho T, Vitória A, Ferreira A, Santos R, Rocha $\mathrm{N}$, et al. Standing balance in individuals with Parkinson' $\mathrm{s}$ disease during single and dual-task conditions. Gait Posture. 2015;42:323-328. doi:10.1016/j.gaitpost.2015.06.188.

11. Fok P, Farrell M, McMeeken J. Prioritizing gait in dual-task conditions in people with Parkinson's. Hum Mov Sci. 2010;29(5):831842. doi:10.1016/j.humov.2010.06.005. 
12. Fuller RL, Van Winkle EP, Anderson KE, Gruber-Baldini AL, Hill T, Zampieri C, et al. Dual task performance in Parkinson's disease: a sensitive predictor of impairment and disability. Park Relat Disord. 2013;19(3):325-328. doi:10.1016/j.parkreldis.2012.11.011.

13. Altmann LJP, Stegemöller E, Hazamy AA, Wilson JP, Okun MS, McFarland NR, et al. Unexpected dual task benefits on cycling in Parkinson disease and healthy adults: A neuro-behavioral model. PLoS One. 2015;10(5):1-13. doi:10.1371/journal.pone.0125470.

14. Yogev-Seligmann G, Rotem-Galili Y, Dickstein R, Giladi N, Hausdorff JM. Effects of explicit prioritization on dual task walking in patients with Parkinson's disease. Gait Posture. 2012;35:641646. doi:10.1016/j.gaitpost.2011.12.016.

15. Bloem B, Valkenburg V, Slabbekoorn M, van Dijk J. The multiple tasks test. Strategies in Parkinson's disease. Exp Brain Res. 2001;137(4-5):478-486.

16. Bloem BR, Grimbergen YAM, Dijk JG Van, Munneke M. The "“ posture second "' strategy : a review of wrong priorities in Parkinson's disease. J Neurol Sci. 2006;248:196-204. doi:10.1016/j. jns.2006.05.010.

17. Plummer P, Eskes G. Measuring treatment effects on dual-task performance: a framework for research and clinical practice. Front Hum Neurosci. 2015;9:1-7. doi:10.3389/fnhum.2015.00225.

18. Christofoletti G, Mcneely ME, Campbell MC, Duncan RP, Earhart GM. Investigation of factors impacting mobility and gait in Parkinson disease. Hum Mov Sci. 2016;49:308-314. doi:10.1016/j. humov.2016.08.007.

19. Magill RA. Aprendizagem Motora: Conceitos e Aplicações. In: Motor Learning: Concepts and Applications. Vol ; 2000:300-319.

20. Hughes AJ, Daniel SE, Kilford L, Lees AJ. Accuracy of clinical diagnosis of idiopathic Parkinson 's disease : a clinico-pathological study of 100 cases. J Neurol Neurosurg Psychiatry. 1992;55:181-184.

21. Schenkman M, Clark K, Xie T, Kuchibhatla M, Shinberg M, Ray L. Spinal movement and performance of a standing reach task in participants with and without Parkinson disease. Phys Ther. 2001;81(8):1400-1411.

22. Brucki SMD, Nitrin R, Caramelli P, Bertolucci PHF, Okamoto IH. Suggestions for utilization of the mini-mental state examination in Brazil. Arq Neuropsiquiatr. 2003;61(3 B):777-781. doi:10.1590/ S0004-282X2003000500014.

23. Nasreddine ZS, Phillips NA, Bédirian V, Charbonneau S, Whitehead V, Collin I, et al. The Montreal Cognitive Assessment, MoCA: A Brief ScreeningTool For Mild Cognitive Impairment. J Am Geriatr Soc. 2005;53(4):695-699.

24. Goetz CG, Tilley BC, Shaftman SR, Stebbins GT, Fahn S, MartinezMartin P, et al. Movement Disorder Society-sponsored revision of the Unified Parkinson's Disease Rating Scale (MDS-UPDRS): Scale presentation and clinimetric testing results. Mov Disord. 2008;23(15):2129-2170. doi:10.1002/mds.22340.

25. Goetz CG, Poewe W, Rascol O, Sampaio C, Stebbins GT, Counsell $\mathrm{C}$, et al. Movement Disorder Society Task Force report on the Hoehn and Yahr staging scale: status and recommendations. Mov Disord. 2004;19(9):1020-1028. doi:10.1002/mds.20213.

26. Shulman LM, Armstrong M, Ellis T, Gruber-Baldini A, Horak F, Nieuwboer A, et al. Disability rating scales in Parkinson ' $\mathrm{s}$ Disease : critique and recommendations. Mov Disord. 2016:1-12. doi:10.1002/mds.26649.
27. Lezak M, Howieson D, Loring D. Neuropsychological Assessment. New York: Oxford University Press; 2004.

28. Mitrushina M, Boone KB, Razani J, D'Elia LF. Handbook of Normative Data for Neuropsychological Assessment. Vol Second Edi. New York: Oxford University Press; 2005.

29. Strauss E, Sherman E, Spreen R. A Compendium of Neuropsychological Tests: Administration, Norms and Commentary. Vol Third edit. New York: Oxford University Press; 2006.

30. Krampe R, Schaefer S, Lindenberger U, Baltes PB. Lifespan changes in multi-tasking : Concurrent walking and memory search in children, young, and older adults. Gait Posture. 2011;33(3):401-405. doi:10.1016/j.gaitpost.2010.12.012.

31. Schmidt R, Lee T. Motor Control and Learning: A Behavioral Emphasis. Vol 5th ed. Humam Kinetics; 1999.

32. Duncan RP, Leddy AL, Earhart GM. Five times sit-to-stand test performance in Parkinson's disease. Arch Phys Med Rehabil. 2011;92(9):1431-1436. doi:10.1016/j.apmr.2011.04.008.

33. Podsiadlo D, Richardson S. The Timed "Up \& Go": A test of basic functional mobility for frail elderly persons. J Am Geriatr Soc. 1991;39:142-148.

34. Novaes RD, Miranda AS, Dourado VZ. Usual gait speed assessment in middle-aged and elderly Brazilian subjects. Rev Bras Fisioter. 2011;15(2):117-122. doi:10.1590/S1413-35552011000200006.

35. McDowd J. The effects of age and extended practice on divided attention performance. J Gerontol. 1986;41(6):764-769.

36. Spildooren J, Vercruysse S, Desloovere K, Vandenberghe W, Kerckhofs E, Nieuwboer A. Freezing of Gait in Parkinson's Disease: The Impact of Dual-Tasking and Turning. Mov Disord. 2010;25(15):2563-2570. doi:10.1002/mds.23327.

37. Bartmann L, Daiane W, Lima B De, Bisol J, Luana B, Peyre LA. Characterization of cognitive and motor performance during dual-tasking in healthy older adults and patients with Parkinson 's disease. J Neurol. 2013;260:580-589. doi:10.1007/ s00415-012-6683-3.

38. Al-Yahya E, Dawes H, Smith L, Dennis A, Howells K, Cockburn J. Cognitive motor interference while walking: A systematic review and meta-analysis. Neurosci Biobehav Rev. 2011;35(3):715-728. doi:10.1016/j.neubiorev.2010.08.008.

39. Bond JM, Morris M. Goal-directed secondary motor tasks: Their effects on gait in subjects with Parkinson disease. Arch Phys Med Rehabil. 2000;81(January):110-116. doi:10.1053/ apmr.2000.0810110.

40. Rochester L, Galna B, Lord S, Burn D. The nature of dual-task interference during gait in incident Parkinson's disease. Neuroscience. 2014;265:83-94. doi:10.1016/j.neuroscience.2014.01.041.

41. Jacobs J V, Nutt JG, Carlson-Kuhta P, Allen R, Horak FB. Dual tasking during postural stepping responses increases falls but not freezing in people with Parkinson's disease. Park Relat Disord. 2014;20(7):779-781. doi:10.1016/j.parkreldis.2014.04.001.

42. Nocera J, Roemmich R, Elrod J, Altmann L, Hass C. Effects of cognitive task on gait initiation in Parkinson disease: Evidence of motor prioritization? J Rehabil Res Dev. 2013;50(5):699-708.

43. Broede r S, Nackaerts E, Nieuwboer A, Smits-Engelsman B, Swinnen S, Heremans E. The effects of dual tasking on handwriting in patients with Parkinson's disease. Neuroscience. 2014;28(263):193-202. 
44. Lawson RA, Yarnall AJ, Duncan GW, Breen DP, Khoo TK, Williams-Gray $\mathrm{CH}$, et al. Cognitive decline and quality of life in incident Parkinson's disease: The role of attention. Parkinsonism Relat Disord. 2016;4:1-27. doi:10.1016/j.parkreldis.2016.04.009.

45. Schönberger AR, Barbe MT, Hagelweide K, Kühn AB, Fink GR, Schubotz RI. Joint principles of motor and cognitive dysfunction in Parkinson's disease. Neuropsychologia. 2013;51(8):1417-1425. doi:10.1016/j.neuropsychologia.2013.04.011.

46. Maetzler W, Liepelt I, Berg D. Progression of Parkinson's disease in the clinical phase: potential markers. Lancet Neurol. 2009;8(12):1158-1171. doi:10.1016/S1474-4422(09)70291-1.

47. Yogev G, Giladi N, Peretz C, Springer S, Simon ES, Hausdorff JM. Dual tasking, gait rhythmicity, and Parkinson's disease: which aspects of gait are attention demanding? Eur J Neurosci. 2005;22:1248-1256.

48. Galletly R, Brauer SG. Does the type of concurrent task affect preferred and cued gait in people with Parkinson's disease? Aust J Physiother. 2005;51(3):175-180. doi:10.1016/ S0004-9514(05)70024-6.

49. Rodrigues AB, Yamashita E, Chiappetta A. Verbal fluency test in adult and elderly: verification of verbal learning. Rev CEFAC. 2008;10(4):443-451.

50. Baker K, Rochester L, Nieuwboer A. The immediate effect of attentional, auditory, and a combined cue strategy on gait during single and dual tasks in Parkinson's disease. Arch Phys Med Rehabil. 2007;88(12):1593-1600. doi:10.1016/j.apmr.2007.07.026.

51. Barbosa AF, Souza C de O, Chen J, Francato DV, Caromano FA, Chien HF, et al. The competition with a concurrent cognitive task affects posturographic measures in patients with Parkinson disease. Arq Neuropsiquiatr. 2015;73(11):906-912. doi:10.1590/0004-282X20150153.
52. Strouwen C, Molenaar EALM, Munks L, Keus SHJ, Bloem BR, Rochester L, et al. Dual tasking in Parkinson's disease: should we train hazardous behavior? Expert Rev Neurother. 2015;15(9):10311039. doi:10.1586/14737175.2015.1077116.

53. Fritz N, Cheek FM, Nichols-Larsen DS. Motor-Cognitive dual-task training in neurologic disorders: a systematic review. J Neurol Phys Ther. 2015;39(3):142-153. doi:10.1016/bs.mcb.2015.01.016. Observing.

54. Peterson DS, Dijkstra BW, Horak FB. Postural motor learning in people with Parkinson's disease. J Neurol. 2016;(May):1-13. doi:10.1007/s00415-016-8158-4.

\section{Corresponding author}

Camila Torriani-Pasin

School of Physical Education and Sport, University of São Paulo, Professor Mello Moraes Avenue, 64

Email: camilatorriani@gmail.com

Manuscript received on August 27, 2018

Manuscript accepted on December 4, 2018

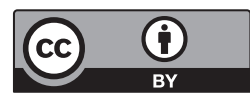

Motriz. The Journal of Physical Education. UNESP. Rio Claro, SP, Brazil - eISSN: 1980-6574 - under a license Creative Commons - Version 4.0 